\title{
Response of METEOSAT water vapour channel (*)
}

\author{
M. Roulleau, M.-M. Poc, N. Scott and A. Chedin \\ Laboratoire de Météorologie Dynamique, Ecole Polytechnique, 91128 Palaiseau Cedex, France
}

(Recu le 8 octobre 1979, rivisí le 3 dicembre 1979, accepté le 20 décembre 1979)

\begin{abstract}
Résumé. - Un modèle précis de transmission atmosphérique est utilisé pour obtenir la relation liant les valeurs de l'énergie radiante mesurée en ciel clair par le radiomètre 6-7 $\mu$ (canal vapeur d'eau) du satellite METEOSAT aux valeurs de la variable numérique associée à chaque point d'une image. Cette relation est comparée à la courbe d’étalonnage provisoire publiée par l'Agence Spatiale Européenne.
\end{abstract}

\begin{abstract}
An accurate model of the atmospheric transmission function is used to obtain the relationship between the cloudless radiances measured by the 6-7 $\mu \mathrm{m}$ METEOSAT radiometer (water vapour channel) and the numerical parameters associated to each point of an image. This relationship is compared to the temporary calibration curve published by the European Space Agency.
\end{abstract}

METEOSAT is the first geostationary satellite having a scanning radiometer containing a water vapour channel $(5.6 \mu \mathrm{m}-7.5 \mu \mathrm{m})$. This satellite provides an image every half hour from the same points of the earth. The spatial and temporal evolution of water vapour patterns is observed from consecutive images. Up to now, satellite observations in this spectral interval were done with polar orbiting satellites (for example TIROS and NIMBUS). But, then, only two pictures a day of the same geographical zone were available. Under cloudless conditions (avoiding, in particular, high altitude cirrus clouds), the radiation emitted in the water vapour channel is related to the mean relative humidity above $600 \mathrm{mb}$ level [1]. Several authors [2, 3, 4], deduced global tropospheric relative humidity from these data. In this region where water vapour can be considered as a tracer of atmospheric motions, qualitative dynamical studies have also been conducted using radiometric observations $[5,6,7]$.

An actual quantitative analysis of METEOSAT water vapour data requires the 6-7 $\mu \mathrm{m}$ channel calibration. The signal received by the radiometer appears on the magnetic tape as a numerical value coded between 0 and 256 . The calibration gives the relationship between this coded value and the outgoing radiation. The METEOSAT water vapour calibra-

$\left(^{*}\right)$ La version française de cet article a été acceptée aux Comptes Rendus de l'Académie des Sciences et est insérée dans le $\mathrm{n}^{\circ} \mathrm{du}$ 10 décembre 1979. tion is not available and could only be realized a posteriori using indirect processes. Up to now, the European Space Operations Centre has only published a temporary calibration curve [8].

This relation can be calculated through the radiative transfer equation which connects the radiative energy received by the radiometer to the meteorological parameters of the atmosphere. These computations are made at definite geographical points chosen for the availability of complete humidity and pressure soundings, and the results are compared to the numerical values associated to each point of a clear sky picture. The calculations are carried out with a line-by-line transmission model now available in our laboratory. From the line parameters of the molecules absorbing in the spectral range covered by the radiometer filter, this model determines high resolution transmission functions and radiances through the atmosphere, the latter being convolved by the apparatus function to give the synthetic radiant energy. This model for computing atmospheric transmissions and radiances has been extensively described in two previous publications $[9,10]$; it is based upon direct integrations in altitude and in frequency owing to the use of the fine structure parameters of the absorption bands. In order to adapt the general model to this particular problem, a previous study of a THIR picture of the NIMBUS-5 satellite (which calibration was known) was made. The calculated radiances so obtained were shown to be in fairly good agreement with the observed experimental values (see table I of Ref. [11]). 
For both THIR-NIMBUS-5 and the water vapour METEOSAT channels, the transmittances were calculated with an integration step of $2.5 \times 10^{-3} \mathrm{~cm}^{-1}$ which is the mean value of the Doppler half-width of the water vapour lines. The line shape profile is cut off beyond 100 half-widths from the line centre. In the spectral interval covered by the water vapour METEOSAT channel $\left(1342 \mathrm{~cm}^{-1}\right.$ to $\left.1774 \mathrm{~cm}^{-1}\right)$, water vapour can be considered as the only absorbing gas. The atmosphere is divided into 20 layers distributed at pressure levels between $1000 \mathrm{mb}$ and $5 \mathrm{mb}$. The radiation intensities $(I)$ are calculated through the radiative transfer equation on intervals of $0.5 \mathrm{~cm}^{-1}$ which value was chosen in order to keep a correct representation of the Planck and the filter function variations.

We studied July 14 and 16, 1978, pictures at 12 GMT in the geographical region centred between $30^{\circ} \mathrm{N}$ and $55^{\circ} \mathrm{N}$ and between $20^{\circ} \mathrm{W}$ and $25^{\circ} \mathrm{E}$, that is mainly the occidental part of Europe and Mediterranean Basin. At this date, the detector of the radiometer was regulated at $90 \mathrm{~K}$, and the associated filter function was taken into account in the calculations. In this area, there is a sufficient number of stations of the international meteorological network. The cloudless atmospheric data are obtained from the radiosoundings. METEOSAT is placed in geostationary position at $0^{\circ}$ longitude, then, for the chosen geographical region, the zenith angles at the stations are rather large (around $50^{\circ}$ ). In the water vapour channel, the ground resolution is of $5 \mathrm{~km}$ at subsatellite point, then, with a zenith angle of about $50^{\circ}$, the ground resolution is of about $8 \mathrm{~km}$. Obviously the absorbing water vapour mass is dependent upon the zenith angle which was introduced accurately in the model for each of the radiosounding stations. These stations are localized by mean of an interactive computer system for image vizualization. Landmarks are pointed from the corresponding picture in the visible channel and, using a navigation program which takes into account the position parameters of the satellite, the stations are mapped with an accuracy better than 4 pixels. The ground distance of 4 pixels is of about the mean horizontal trajectory of a radiosounding balloon ascending to the tropopause.

Once each station is localized on the picture, the numerical value given by METEOSAT water vapour channel is extracted and compared to the radiance calculated from the radiosounding data. The results obtained are given in the table I and shown on figure 1. Calculations were performed for nineteen stations. Both the computation time (about $0.7 \mathrm{~s}$ per $1 \mathrm{~cm}^{-1}$ with a $370 / 168$ IBM computer) and the number of cloudless complete soundings available limit the studied cases. Uncertainties in the atmospheric profiles (temperature, humidity) and in the geographical localization on the pictures are the most crucial points which may explain the scattering of the results around the straight line obtained through leastsquares regression analysis. This line is practically parallel to the temporary calibration curve obtained with a different method, published by the European Space Operations Centre. The errors in the calculated atmospheric transmissions and radiances cannot be responsible for the difference between the two lines in figure 1 , which represents about $8 \mathrm{~K}$.

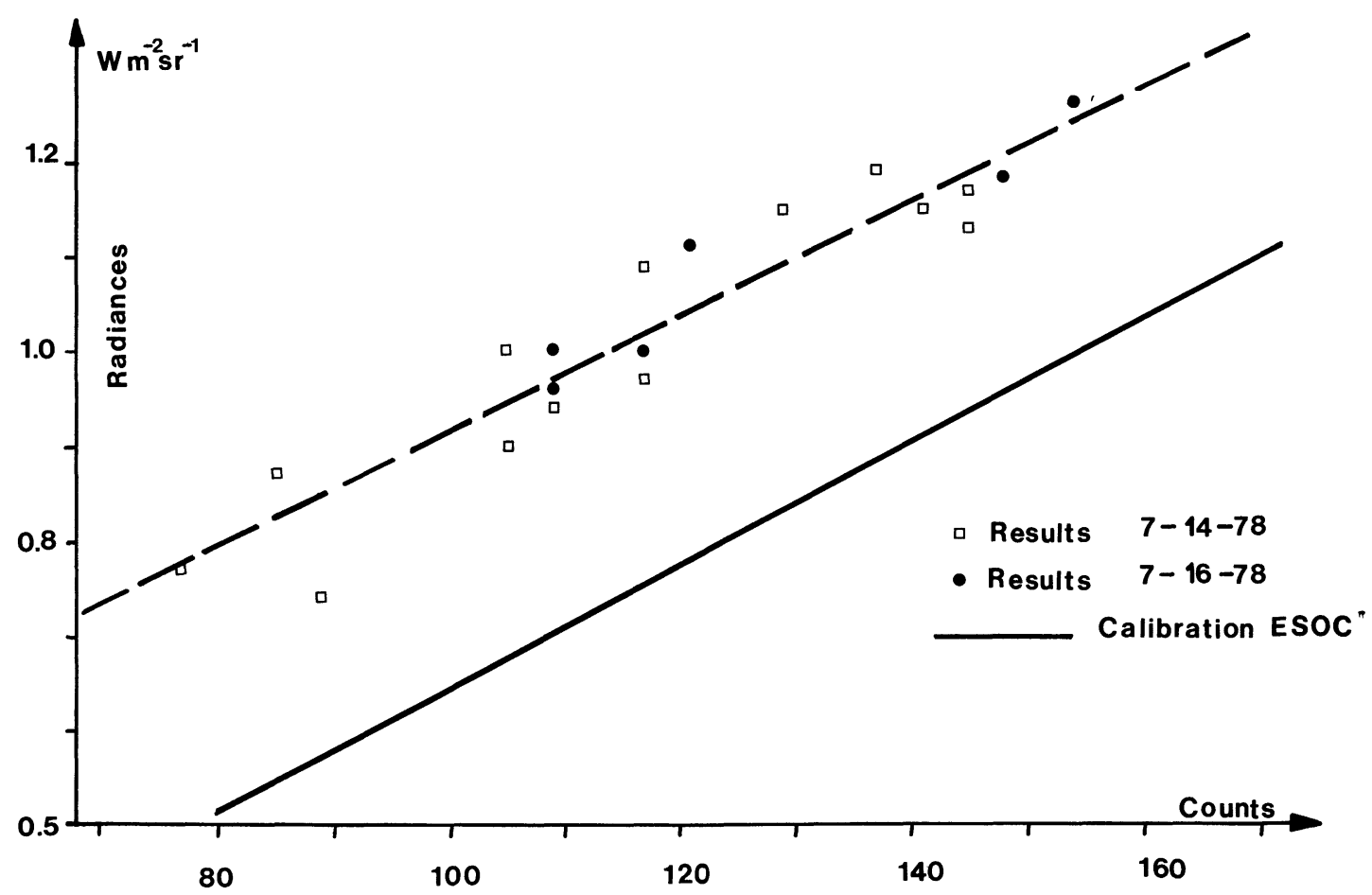

Fig. 1. - Response of METEOSAT water vapour channel : radiances versus counts. 
Table I. - Calculated radiances and digital counts for the two METEOSAT W.V. pictures (July 14,1978 and July 16, 1978 at 12 GMT).

\begin{tabular}{|c|c|c|c|c|c|c|c|c|}
\hline \multicolumn{6}{|c|}{14 jul. 1978} & \multicolumn{3}{|c|}{16 jul. 1978} \\
\hline Stations & $\begin{array}{c}I \\
\mathrm{Wm}^{-2} \mathrm{sr}^{-1}\end{array}$ & Count & Stations & $\begin{array}{c}I \\
\mathrm{Wm}^{-2} \mathrm{sr}^{-1}\end{array}$ & Count & Stations & $\begin{array}{c}I \\
\mathrm{Wm}^{-2} \mathrm{sr}^{-1}\end{array}$ & Count \\
\hline- & - & - & - & - & - & - & - & - \\
\hline Ajaccio & 1.09 & 117 & Idris & 1.17 & 145 & Ajaccio & 1.00 & 117 \\
\hline Belfast & 0.77 & 77 & Lisbonne & 1.13 & 145 & Lisbonne & 1.11 & 121 \\
\hline Belgrade & 1.00 & 105 & Lyon & 0.90 & 105 & Malte & 1.18 & 148 \\
\hline Bordeaux & 0.97 & 117 & Malte & 1.19 & 137 & Nîmes & 1.00 & 109 \\
\hline Brest & 0.74 & 89 & Nîmes & 0.94 & 109 & Rome & 0.96 & 109 \\
\hline Funchal & 1.15 & 129 & Udine & 0.87 & 85 & Tunis & 1.26 & 154 \\
\hline
\end{tabular}

Later this year a moon calibration project will be realized by ESOC and this will lead to a new comparison. Furthermore we use these results for a three- dimensional quantitative analysis of the water vapour patterns in cloud free area in middle and tropical latitudes.

\section{References}

[1] Moller, F. and Raschke, E., NASA Report n" CR-112 NASA, 1964, 84.

[2] RaSChKe, E. and Bandeen, W. R., J. Appl. Meteorol. 6 (1967) 468.

[3] Fritz, S. and RaO, P. K., J. Appl. Metcorol. 6 (1967) 1088.

[4] Allison, L. J. et al., Bull. Am. Meteorol. Soc. 53 (1972) 526.

[5] Steranka, J. et al., J. Appl. Metcorol. 12 (1973) 1386.

[6] Rodgers, E. B. et al., J. Geophys. Res. 81 (1976) 5749.
[7] Roulleau, M., Remote Sensing of the Atmosphere : Inversion Methods and Applications (Els. Sci. Pub. Co.) 1978, p. 149.

[8] Morgan, J., ESOC. Calibration Report 1979.

[9] Scotr, N., J. Quant. Spectrosc. Radiat. Transfer 14 (1974) 691.

[10] Chedin, A. et al., J. Mol. Spectrosc. 78 (1978) 343.

[11] Poc, M. M. et al., Remote Sounding on the Atmosphere from Space (COSPAR) (Perg. Pr. Oxford) 1979, p. 169. 